\title{
Knowledge Among Nurses Regarding Post-Partum Depression In A Tertiary Hospital Setting Of Nepal
}

\author{
Gurung $S^{1}$, Shah $\mathbf{S}^{2}$, Lamichhane $\mathrm{K}^{3}$ \\ 1. Associate Professsor, Universal College of Nursing Sciences, Bhairahawa, Nepal 2. Lecturer, Dept. Of \\ Psychiatry, UCMS, Bhairahawa, Nepal 3. Lecturer, Universal College of Nursing Sciences, Bhairahawa, \\ Nepal
}

E-mail *Corresponding author: g.saraj@gmail.com

\begin{abstract}
Introduction: Postpartum depression is an important health problem which influences well-being, quality and security of life and may cause more serious problems than major depression occurring in normal life periods. It has an adverse influence on self-esteem, skills, child care, familial responsibility and roles of the mother. The aim of the study was to find out nurses' knowledge regarding postpartum depression.

Material And Method: Descriptive study design was used to find out the knowledge regarding postpartum depression among nurses. Seventy-four nurses were selected from general and critical care units of a hospital by non probability enumerative sampling technique for the study. Data was collected by pre tested self-administered semistructured questionnaire and collected data was analyzed by descriptive statistics (frequency, percentage, mean and standard deviation) with SPSS version 20.

Results: Fifty percent of respondents knew postpartum depression (PPD) is a type of mood disorder associated with childbirth. Majority of respondents knew poor marital relationship (85\%), unwanted and unplanned pregnancy $(83.88 \%)$, previous mental illness $(78.40 \%)$ and lack of family support $(66.20 \%)$ are risk factors of PPD. Regarding symptoms of PPD respondents knew low energy $(78.37 \%)$, extreme sadness $(68.91 \%)$, changes in sleeping and eating pattern $(67.56 \%)$ and crying $(66.21 \%)$. Eighty percentages of the respondents knew PPD can be identified by observation and antidepressant drug (88\%) and psychotherapy (83.78\%) are medical management of PPD. Majority of respondents knew nursing management of PPD are maintaining close observation of mother $(93.24 \%)$, maintaining safe environment (86.48\%) and family counseling (83.78\%). Eighty one percentage respondents knew poor mother infant attachment is main consequence of PPD in child and poor relationship (54.05\%), suicide $(33.79 \%)$ and harm to baby (12\%) in mother. Fifty four percentages had low knowledge regarding PPD.
\end{abstract}

Conclusion: It is concluded that knowledge regarding PPD is inadequate among nurses. It is recommended that hospital management should provide in-service education to nurses to uplift their professional knowledge regarding $P P D$ and encourage applying knowledge in practice during care of women with PPD.

Keywords: Nurses, Knowledge, Postpartum Depression

\section{INTRODUCTION}

Postpartum depression (PPD) is one of the major psychological disorders worldwide that affects both mother and child. ${ }^{1}$ Postnatal depression is a type of mood disorder associated with childbirth, which can affect both sexes. While the exact cause of PPD is unclear, the cause is believed to be a combination of physical and emotional factors. Risk factors include prior episodes of postpartum depression, bipolar disorder, a family history of depression, psychological stress, complications of childbirth, lack of support, or substance use disorder. ${ }^{2}$

PPD is manifested as persistent feeling of sadness and low mood, lack of enjoyment and loss of interest in the outer world, lack of energy 
and feeling tired all the time, trouble sleeping at night and feeling sleepy during day time, difficulty bonding with baby, withdrawing from contact with other people, problems in concentrating and making decisions, frightening thoughts, sleeping/eating disturbance, anxiety/insecurity, emotional liability, mental confusion, loss of self control, guilt/shame and suicidal thought. ${ }^{3}$

The prevalence of postpartum depression worldwide varies from 0.5 to $60.8 \%$ in the first months of postpartum. The prevalence of postpartum depression varies from $1.9 \%$ to $82.1 \%$ in the developing countries and from $5.2 \%$ to $74 \%$ in developed countries. ${ }^{4}$ In Nepal, the prevalence of postpartum depression is currently considered to be $10-15 \%$. However, there is wide range of reported prevalence of postpartum depression ranging from $0-60 \% .^{5}$

PPD encompasses several mood disorders that follow childbirth and affects $10-15 \%$ of all new mothers, but its prevalence may be as high as $35 \%$ in certain demographic groups. PPD is under diagnosed and remains the most common complication of childbirth and the most common perinatal psychiatric disorder, with women at greatest risk during their first postpartum year $(45-65 \%$ of ever depressed women). ${ }^{6}$

Many cases of PPD may remain undiagnosed due to constraints such as time and concerns about the social acceptability of screening. But the majority of undiagnosed cases are probably due to the social stigma of being labeled an "unhappy mother," not to mention the public image of PPD. ${ }^{7}$ Upon formal screening, many women scoring in a depressive range fully admit to being depressed, understanding that their symptoms are neither minor nor transient. But they reject the term "postpartum depression" because this implies to them that their feelings are caused by their babies. ${ }^{8}$ For women, it is the stigma of PPD that causes shame, fear, embarrassment, and guilt. ${ }^{9}$

A study ${ }^{10}$ of Saudi Arabia on 2018 shows that nurses and midwives lack knowledge about various aspect of postpartum depression including its definition, prevalence, symptoms, risk factors, screening tools, and treatment. Only one third of participants were confident in their ability to provide education for women about PPD.

\section{MATERIAL AND METHOD}

Descriptive study design was used to find out the knowledge regarding postpartum depression among nurses. The study was conducted in general and critical care units of Universal College of Medical Sciences-Teaching Hospital, Rupandehi district, Nepal. Seventyfour nurses were selected as the sample of the study by non probability enumerative sampling technique. Pre tested self-administered semistructured questionnaire (17 questions were included) was prepared by researchers by reviewing the related literatures and consulting gynecologists and psychiatrist. Data was collected within two weeks of period from $17^{\text {th }}$ to 29th March 2019. Administrative and ethical approval was obtained from concerned authorities prior to data collection.

Researchers obtained the name list of nurses from duty register of each ward of Universal College Medical Sciences-Teaching Hospital. Then, researchers collected data just before the change of each duty shift of nurses by taking written informed consent voluntarily from each respondent. Descriptive statistics (frequency, percentage, mean and standard deviation) method was used with SPSS version 20 .

\section{RESULT}

Regarding socio-demographic variables of respondents $60.80 \%$ of respondents were $19-23$ years, mean age was 22.90 and standard deviation was 2.649. $51.40 \%$ had work experience of below 2 years and $45.90 \%$ had worked in gynae/obstetric ward.

Regarding the meaning of postpartum depression (PPD), 50\% of respondents knew it is a type of mood disorder associated with childbirth and $60.80 \%$ knew estrogen and progesterone hormone is responsible for PPD (not shown in table). Eighty five percentages of respondents knew poor marital relationship, unwanted and unplanned pregnancy $(83.88 \%)$, previous mental illness (78.40\%), pregnancy loss $(68.90 \%)$, lack of family support $(66.20 \%)$ an neonatal illness $(27.00 \%)$ are risk factors of PPD respectively (table 1).Thirty percentages of respondents answered symptoms of PPD occur at first 4 to 6 weeks of child birth (not shown table). Regarding symptoms of PPD, $78.37 \%$ of respondents knew low energy, extreme sadness 
$(68.91 \%)$, and changes in sleeping and eating pattern $(67.56 \%)$, crying $(66.21 \%)$ and anxiety and irritability $(64.86 \%)$ were the symptoms (Table 2).

$80 \%, 21.61 \%$ and $10.81 \%$ of the respondents answered observation method, history taking and mental state examination are the method of diagnosis of PPD. Ninety five percentage and $35 \%$ of respondents answered PPD is treatable and cured within 6 months of child birth (not shown in table). About $88 \%, 83.78 \%$ and $32.43 \%$ of the respondents answered antidepressant drug, psychotherapy and hormonal therapy are medical management of PPD. Respondents knew nursing management of PPD are close observation of mother (93.24\%), maintaining safe environment $(86.48 \%)$, family counseling $(83.78 \%)$, politely providing nursing care $(70.27 \%)$, allowing friends and relatives for social support $(64.86 \%)$ and encouraging to ventilate feeling $(54.05 \%)$ respectively (table 3 ).

Regarding effects of PPD respondents answered that poor mother infant attachment $(81.10 \%)$, poor social relationship (54.05\%), and cognitive problem in children $(51.40 \%)$, behavior problem in children $(48.61 \%)$, suicidal thought $(33.79 \%)$ and harm to baby (12.16\%) (Table 4) and 54\% percentage of the respondents had low knowledge regarding PPD (table 5).

Table 1: Respondents' knowledge regarding risk factors of postpartum depression $(n=74)$

\begin{tabular}{l|r|r|}
\hline \multicolumn{1}{l|}{ Risk Factors $^{* *}$} & Frequency & Percentage \\
\hline Previous mental illness* & 58 & 78.40 \\
Pregnancy loss* & 51 & 68.90 \\
Ethnicity & 2 & 2.70 \\
Neonatal illness* & 20 & 27.00 \\
Unwanted and & 62 & \\
unplanned pregnancy * & 10 & 83.80 \\
Level of education & 63 & 13.50 \\
Poor marital relationship* & 27 & 85.10 \\
Maternal age & 2 & 36.50 \\
Parity & 49 & 2.70 \\
Lack of family support* & ${ }^{*}$ Correct response; ${ }^{* *}$ Multiple response \\
\hline \multicolumn{2}{|c}{} \\
\hline
\end{tabular}

Table 1: Respondents' knowledge regarding Symptoms of Post Partum Depression

\begin{tabular}{|l|c|r|}
\hline Clinical Feature $^{* *}$ & Frequency & Percentage \\
\hline Extreme sadness* $^{*}$ & 51 & 68.91 \\
Delusion & 19 & 25.67 \\
Low energy* & 58 & 78.37 \\
Hallucination & 36 & 48.90 \\
Crying* & 49 & 66.21 \\
Anxiety and irritability* & 48 & 64.86 \\
Illusion & 16 & 21.62 \\
Changes in sleeping & 50 & 67.56 \\
and eating pattern * & & \\
\hline \multicolumn{2}{|c|}{${ }^{*}$ Correct response; ${ }^{* *}$ Multiple response } \\
\hline
\end{tabular}

Table 3. Respondents' knowledge regarding identification and management of PPD

\begin{tabular}{|c|c|c|}
\hline \multirow[t]{2}{*}{ Variables } & \multicolumn{2}{|c|}{ Correct Response } \\
\hline & Frequency & Percentage \\
\hline Identification of PPD & & \\
\hline History taking & 16 & 21.62 \\
\hline Observation & 59 & 79.72 \\
\hline Mental Status Examination & 8 & 10.81 \\
\hline Medical management of PPD & & \\
\hline Antidepressant drug & 65 & 87.83 \\
\hline Psychotherapy & 62 & 83.78 \\
\hline Hormonal therapy & 24 & 32.43 \\
\hline Nursing management & & \\
\hline Encourage to ventilate feeling & 40 & 54.05 \\
\hline $\begin{array}{l}\text { Maintain close observation } \\
\text { of mother }\end{array}$ & 69 & 93.24 \\
\hline Maintain safe environment & 64 & 86.48 \\
\hline $\begin{array}{l}\text { Allow friends and relatives } \\
\text { for social support }\end{array}$ & 48 & 64.86 \\
\hline $\begin{array}{l}\text { Counseling husband and } \\
\text { family members }\end{array}$ & 62 & 83.78 \\
\hline Politely provide nursing care & 52 & 70.27 \\
\hline
\end{tabular}

Table 4: Respondents' knowledge regarding effects of PPD

\begin{tabular}{|lr|r|}
\hline Effects PPD ** & \multicolumn{2}{c|}{ Correct Response } \\
\cline { 2 - 3 } & Frequency & Percentage \\
\hline Poor relationship & 40 & 54.01 \\
Suicidal thoughts & 25 & 33.78 \\
Harm to baby & 9 & 12.16 \\
Poor mother infant attachment & 68 & 81.10 \\
Behavior problem in child & 36 & 48.61 \\
Cognitive problem in child & 38 & 51.40 \\
\hline \multicolumn{2}{c}{ *Correct response; ${ }^{* *}$ Multiple response } \\
\hline
\end{tabular}


Table 5: Respondents' Level Of Knowledge regarding PPD

\begin{tabular}{|l|c|c|}
\hline $\begin{array}{l}\text { Level of } \\
\text { knowledge }\end{array}$ & Frequency & Percentage \\
\hline High & 34 & 45.94 \\
\hline Low & 40 & \multicolumn{2}{|c|}{54.05} \\
\hline Total & $\mathbf{7 4}$ & $\mathbf{1 0 0}$ \\
\hline
\end{tabular}

Total Score-17

\section{DISCUSSION:}

Descriptive study was used to find out the knowledge regarding postpartum depression among nurses of tertiary hospital of Rupandehi district, Nepal. The study showed that $50 \%$ of the respondents knew PPD is a type of mood disorder associated with childbirth which is not consistent with study ${ }^{11}$ of Ankara, Turkey which shows that $84.4 \%$ of nurses and midwives didn't know the definition of postpartum depression accurately.

The study revealed that $85.10 \%$ and $83.80 \%$ of the respondents had knowledge that poor marital relationship and unwanted/unplanned pregnancy are the risk factors of PPD. The findings of the study is not consistent with study $^{12}$ of Bayesla Nigeria which shows that $63.20 \%$ and $19.30 \%$ of the respondents knew poor marital relationship and unwanted and unplanned pregnancy as the risk factors of postpartum depression.

The study found that previous mental illness $(78.40 \%)$, pregnancy loss $(68.90 \%)$, lack of family support $(66.20 \%)$ an neonatal illness $(27.00 \%)$ are risk factors of PPD respectively. Thirty percentages of respondents answered symptoms of PPD occur at first 4 to 6 weeks of giving child birth.

Regarding symptoms of PPD, $78.37 \%$ of respondents knew low energy, extreme sadness $(68.91 \%)$, sleeping/eating disturbances $(67.56 \%)$, crying $(66.21 \%)$ and anxiety and irritability $(64.86 \%)$. Findings of the study are not consistent with the study 11 conducted in Ankara, Turkey shows $64.1 \%$ of the respondents knew symptoms of PPD. Eighty percentages of respondents knew observation method is diagnosis method of PPD. It is not consistent with the study ${ }^{12}$ which shows $27.8 \%$ of nurses knew the diagnosis method of PPD.

\section{CONCLUSION:}

On the basis of the findings of the study, it is concluded that in overall more than half of the respondents have low knowledge regarding postpartum depression. Bur majority of respondents knew poor marital relationship, unwanted/unplanned pregnancy, previous mental illness, pregnancy loss and lack of family support are risk factors of PPD. Nurses know symptoms of PPD are low energy, extreme sadness, sleeping/eating disturbances, crying and anxiety and irritability. Four fifth of nurses know observation method is diagnosis method of PPD. More than of nurses have knowledge that antidepressant drug and psychotherapy as medical management and nursing management of PPD. More than four fifth of nurses have knowledge that poor mother infant attachment and less than half poor relationship, suicidal thought and harm to baby are effect of PPD.

Nurse' knowledge regarding PPD is inadequate. So, it is recommended that hospital management should provide in-service education to nurses to enhance their knowledge regarding PPD and encourage applying knowledge in practice during care of women with PPD.

ACKNOWLEDGEMENT: Researchers deeply express their heartfelt thanks to all who participated in the study for immense support and cooperation. Researchers express their deep and sincere gratitude to all those experts for their valuable judgment, constructive feedbacks and enlightening suggestions throughout the study. Researchers' heartfelt thanks to UCMS$\mathrm{TH}$ for allowing to conduct the study among the working nurses.

\section{CONFLICT OF INTEREST: None}

\section{REFERENCES:}

1. Alharbi AA, Abdulghani HM. Risk factors associated with postpartum depression in the Saudi population. Neuropsychiatric disease and treatment. 2014;10:311.

2. Paulson JF. Focusing on depression in expectant and new fathers. Psychiatric Times. May 2011; 27(2).

3. Logsdon MC, Tomasulo R, Eckert D, Beck C, Dennis CL. Identification of mothers at risk for postpartum depression by hospital-based perinatal nurses. MCN: The American Journal of Maternal/Child Nursing. 2012 Jul 1;37(4):218-25. 
4. Norhayati MN, Hazlina NN, Asrenee AR, Emilin WW. Magnitude and risk factors for postpartum symptoms: a literature review. Journal of affective Disorders. 2015 Apr 1;175:34-52.

5. Kunwar D, Corey EK, Sharma P, Risal A. Screening for Postpartum Depression and Associated Factors among Women who Deliver at a University Hospital, Nepal. Kathmandu University Medical Journal. 2015 Oct 20;13(1):44-8.

6. Moses-Kolko EL, Roth EK. Antepartum and postpartum depression: healthy mom, healthy baby. Journal of the American Medical Women's Association (1972). 2004;59(3):181-91.

7. Kabir K, Sheeder J, Kelly LS. Identifying postpartum depression: are 3 questions as good as 10?. Pediatrics. 2008 Sep 1;122(3):e696-702.

8. Lumley, Judith. "Attempts to Prevent Postnatal Depression Have Not Included Mental Health Workers, and Have Failed." British Medical Journal. 2005; 331: 5-6.

9. Upadhyay RP, Chowdhury R, Salehi A, Sarkar K, Singh SK, Sinha B, Pawar A, Rajalakshmi AK, Kumar A. Postpartum depression in India: a systematic review and meta-analysis. Bulletin of the World Health Organization. 2017 Oct 1;95(10):706.

10. Elshatarat RA, Yacoub MI, Saleh ZT, Ebeid IA, Raddaha AH, Al-Za'areer MS, Maabreh RS. Perinatal Nurses' and Midwives' Knowledge About Assessment and Management of Postpartum Depression. Journal of psychosocial nursing and mental health services. 2018 Jun 20;56(12):36-46.

11. Bilgili N, Işık SN. Postnatal depression: Midwives' and nurses' knowledge and practices. Erciyes Medical Journal. 2010;32(4):265-74.

12. Afolayan JA, Onasoga OA, Rejuaro FM, Yusuf AR, Onuabueke C. Knowledge of Postpartum Depression and its Associated Risk Factors Among NurseMidwives in a Nigerian Tertiary Hospital. Sierra Leone Journal of Biomedical Research. 2016;8(2):54-65.

13. Jones CJ, Creedy DK, Gamble JA. Australian midwives' awareness and management of antenatal and postpartum depression. Women and Birth. 2012 Mar 1;25(1):23-8. 